\section{AB0273 VERY HIGH, BUT NOT LOWER, RADIOGRAPHIC PROGRESSION LEADS TO AN INCREASE IN HAQ-DI. RESULTS FROM THE SWISS SCQM RA COHORT}

${ }_{\text {R. Mueller }}{ }^{1}$, R. Thalmann ${ }^{1}$, N. Graf ${ }^{2}$, H. Schulze-Koops ${ }^{3}$, J. von Kempis ${ }^{1}$. ${ }^{1}$ Division of Rheumatology, Kantonsspital St. Gallen, St. Gallen; ${ }^{2}$ Graf Biostatistics, Wintertherthur, Switzerland; ${ }^{3}$ Rheumaeinheit, Klinikum der Universität München, Campus Innenstadt, Munich, Germany

Background: Numerous predictors of radiographic progression in RA patients have been identified over the last years. In general, analyses of radiographic progression in RA rather focus on radiographic non-progression or repair. High radiographic progression in spite of therapy has, to our knowledge not been analysed in detail in the last years, neither in RCTs nor in cohort studies.

Objectives: To analyse radiographic, demographical and clinical data in RA patients with high radiographic progression before and after the individual peak radiographic progression.

Methods: We included all RA patients from the Swiss registry SCQM with at least two subsequently scored radiographs. Radiographic destruction was scored using the Ratingen erosion score. To analyse high radiographic progression we selected for the highest (peak) radiographic progression in every individual patient for the analysis. The individual peak radiographic progression was analysed in groups as change of Ratingen scores/year: $0-\leq 10,10-\leq 20,20-\leq 30,>30$ (groups $1-4$, follow up $1998-2015$ ). The baseline disease characteristics were compared using standard descriptive statistics (Kruskal-Wallis or Chi-square tests). The change of DAS 28 and HAQ-DI scores before and after peak progression was analysed with the Wilcoxon signed rank tests.

Results: 3 patients were included into the analysis. 3'049 patients had a peak radiographic progression between 0 and $\leq 10$ /year, 773 between 10 and $\leq 20$, 150 between 20 and $\leq 30$, and 61 of $>30$. All patient groups were within the same age range (mean: 56.5 - 60.5 years). Rheumatoid factor and ACPA were more frequent in patient groups with higher peak radiographic progression (RF: 73.6, 80.0, 88.9, 90.0; ACPA: 66.8, 73.4, 74.3, 82.1, groups 1-4, respectively). When the rate of radiographic progression before and after peak progression was analysed, $69.7 \%, 74.7 \%, 76.9 \%$, and $93.3 \%$ of the patients had a radiographic progression of $25 \%$ or lower as compared to peak progression before and $76.1 \%$, $81.8 \%, 91.1 \%$, and $93.8 \%$ after this peak progression, respectively for patients in groups 1 to 4 (Figure A).

The disease activity, as assessed by DAS 28 , was significantly higher in all patient groups before peak progression and lower thereafter (Figure $B, p<0.001$ ). Average HAQ-DI scores increased after peak radiographic progression in group 4 (Figure $\mathrm{C}, \mathrm{p}=0.005$ ) whereas it is stable or even decreases among the patients of the other patient groups.

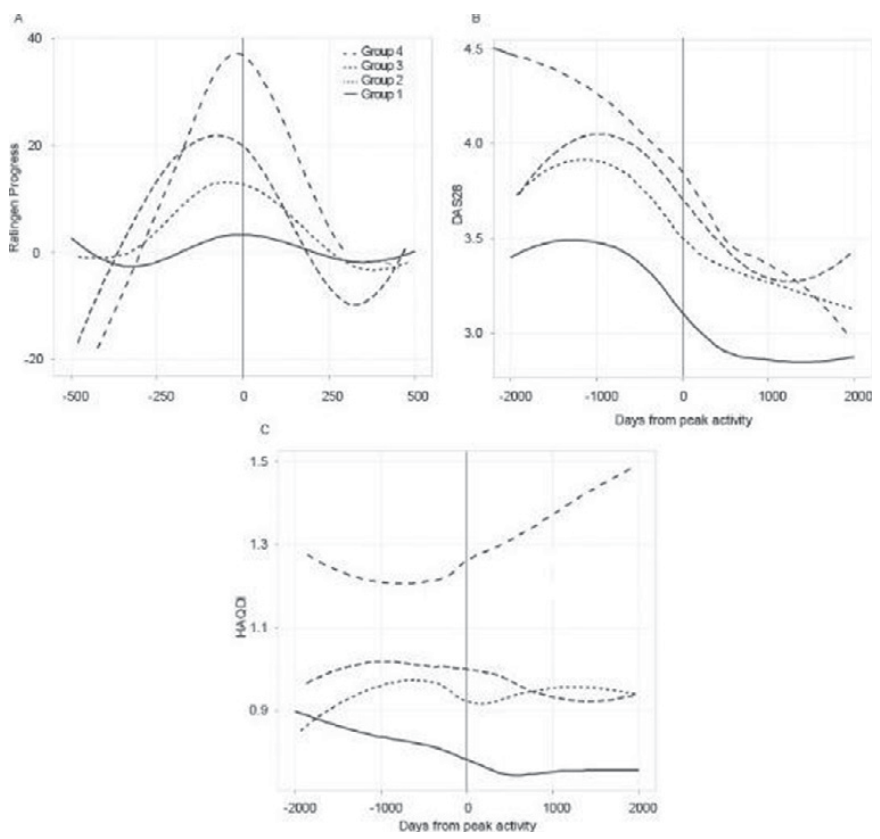

Conclusions: These data show that higher disease activity precedes radiographic peak progression, which is, if high, overall rare. Radiographic progression before and after the individual peak radiographic progression was far lower as compared to the time of radiographic peak progression. Only the highest individual peak (change of Ratingen score $>30$ /year) radiographic progression was followed by an increase of HAQ-DI scores.

Disclosure of Interest: None declared

DOI: 10.1136/annrheumdis-2017-eular.4253

\section{AB0274 THE ASSOCIATION BETWEEN REPEATEDLY INFECTION AND DISEASE OUTCOME IN PATIENTS WITH RHEUMATOID ARTHRITIS}

R. Zhang ${ }^{1}$, J. $\mathrm{He}^{2}, \mathrm{C} . \mathrm{Li}^{2}, \mathrm{~J} . \mathrm{Li}^{2}, \mathrm{~J} . \mathrm{Chen}^{2}, \mathrm{Y} . \mathrm{Jin}^{2}, \mathrm{Y} . \mathrm{Gan}^{2}, \mathrm{Z} . \mathrm{Li}^{2}$ ${ }^{1}$ Department of Rheumatology and Immunology; ${ }^{2}$ Peking University People's Hospital, Beijing, China

Background: Some publications shows some therapies in rheumatoid arthritis (RA) could cause infections and it also can react the disease prognosis. But there was no report about the relationship between the repeated infections during the disease duration and its outcome.

Objectives: Our study was to evaluate the association between the history of repeated infectious agents that occurred more than three times during the duration of RA and the current disease status of RA, such as disease activity and physical disability.

Methods: 688 pure RA patients were selected from December 2015 to June 2016 in Peking People's hospital and divided into two groups according to their current disease status. Clinical data were collected including DAS28, HAQ, disease duration and therapies. Infectious agents occurred repeatedly during the duration were identified as history repeated infectious agents. T test, ANOVA, chi-squared test and multivariate analysis of covariance were used for analyzing the association between the infections and disease outcome.

Results: 688 RA patients were divided into two groups based on whether their DAS28 reached 3.2 (active or inactive). The $\mathrm{HAQ}$ score and the incidence of airway infection has a significant difference among these two groups $(P=0.000 ; P=0.002)$. Logistic regression analysis shows that smoking, airway infection and age were the risk factor for $\mathrm{RA}$ activite $(\mathrm{OR}=4.844,95 \% \mathrm{Cl}(0.193,1.001)$; $\mathrm{OR}=1.326,95 \%$ $\mathrm{Cl}(0.655,2.687) ; \mathrm{OR}=1.013,95 \% \mathrm{Cl}(0.989,1.037))$, and the disease duration and the therapy were also effect the disease outcome (OR=0.650;OR=1.560). Than we divided these patients into four groups based on their infectious site such as airway, urinary, intestinal and no-infection. After adjusting for the disease duration, only airway infection incidence has statistically significantly different $(P=0.000)$. DAS 28 has statistical different only among the groups whether they have airway infectious agents after adjusting the smoking and therapy $(P=0.002$; $\mathrm{P}=0.002)$. Compared with infection free group, patients with airway infection has a higher DAS28 because they have more swollen or painful joints, while patients with urinary infection perform a higher scores because they have a high level of ESR

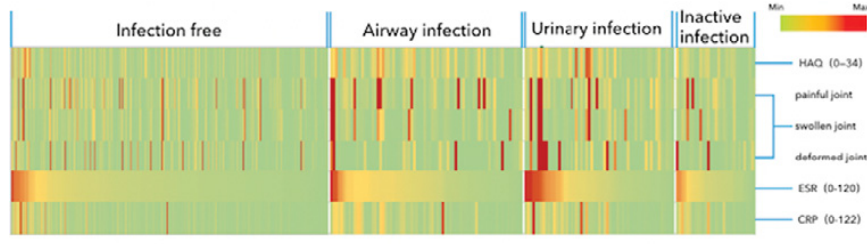

Figure 1. Levels of clinical data include $H A Q$, abnormal joints number, $E S R$ and $C R P$ were compared among subgroups of infection free $(n=469)$, airway $(n=121)$, urinary $(n=75)$ and inactive infection $(n=81)$.This figure shows which factor contribute to the difference of disease activity between subgroups.

Conclusions: The repeated infectious agents during the disease duration might lead to poor outcome. We should pay more attention to those patients who have repeatedly infectious agents during their disease duration in order to improve their prognosis.

References:

[1] Sokolove J, Wagner CA, Lahey LJ, et al. Increased inflammation and disease activity among current cigarette smokers with rheumatoid arthritis: a crosssectional analysis of US veterans. Rheumatology (Oxford). 2016;55(11):196977.

[1] Sokolove J, Wagner CA, Lahey LJ, et al. Increased inflammation and disease activity among current cigarette smokers with rheumatoid arthritis: a crosssectional analysis of US veterans. Rheumatology (Oxford). 2016;55(11):196977.

[2] Iguchi-Hashimoto $M$, Hashimoto $M$, Fujii $T$, et al. The association between serious infection and disease outcome in patients with rheumatoid arthritis. Clin Rheumatol. 2016;35(1):213-8.

Disclosure of Interest: None declared

DOI: 10.1136/annrheumdis-2017-eular.3976

\section{AB0275 THE CORRELATION OF CARTILAGE OLIGOMERIC MATRIX PROTEIN WITH SONOGRAPHIC KNEE CARTILAGE THICKNESS AND DISEASE CHARACTERISTICS IN RHEUMATOID ARTHRITIS}

S. Rajalingham ${ }^{1}$, S. Rajalingam ${ }^{2}$, H. Hussein ${ }^{2}$, R. Sridharan ${ }^{3}$, A.A. Wahab ${ }^{4}$ ${ }^{1}$ Medicine, Universiti Kebangsaan Malaysia, Kuala Lumpur; ${ }^{2}$ Medicine, Putrajaya Hospital, Putrajaya; ${ }^{3}$ Radiology; ${ }^{4}$ Microbiology, Universiti Kebangsaan Malaysia, Kuala Lumpur, Malaysia

Background: Cartilage Oligomeric Matrix Protein (COMP) is an extracellular protein which is primarily found in the cartilage and to a lesser extent in ligaments, meniscus, tendons and synovium. Experimental models of rheumatoid arthritis (RA) and osteoarthritis have pointed out that serum COMP levels are reflective of the cartilage turnover rate. 